easily pulled down until its upper border is on a level with the anterior superior iliac spine. The other two bands are very quickly put in position, one beneath the calf of the leg, and the other attached to the same end-piece as the shoulder band, under the head (Fig. 1). The placing of all these straps is very rapidly done, being only a matter of a couple of minutes, and can all be accomplished by one person. The patient can now be lifted by one nurse and lies, when the bands are in their proper places, at perfect rest on them (Fig. 2.).

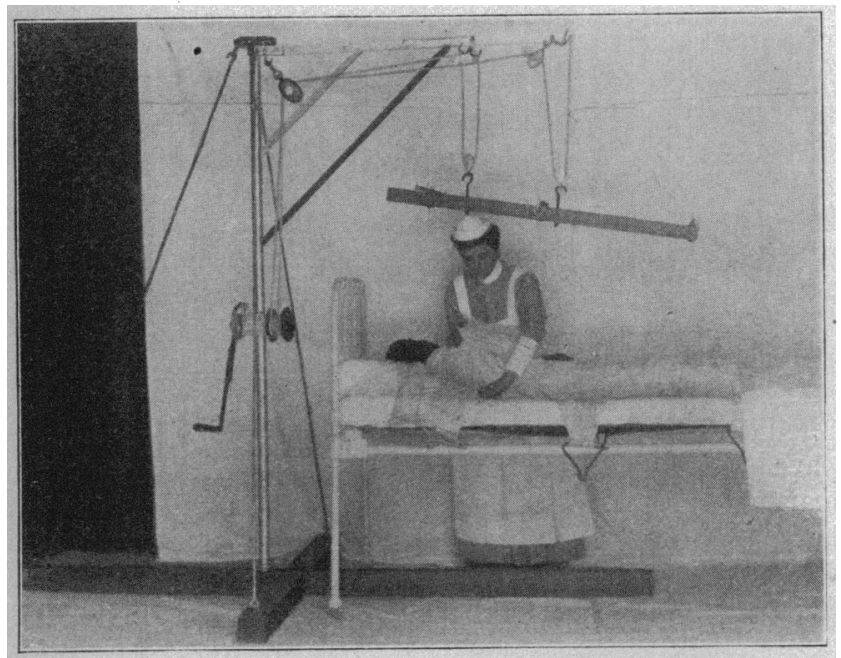

Figure 1.

BENEFITS.

The nurse is then at liberty to change the bed, turn the mattress, introduce the douche pan, or thoroughly rub the patient's back. In cases of any tendency for the development of a bed-sore in a patient who has been obliged to remain for a long time on the back, instead of using one strap beneath the hips, which would rub on the sore, two straps with the bedsore in the interval may be used, and thus the developing bedsore readily dressed. In this case one strap passed beneath the small of the back and the other under the thigh just beneath the buttocks. It will thus be seen that any part of the patient's body can be made accessible. The patient is

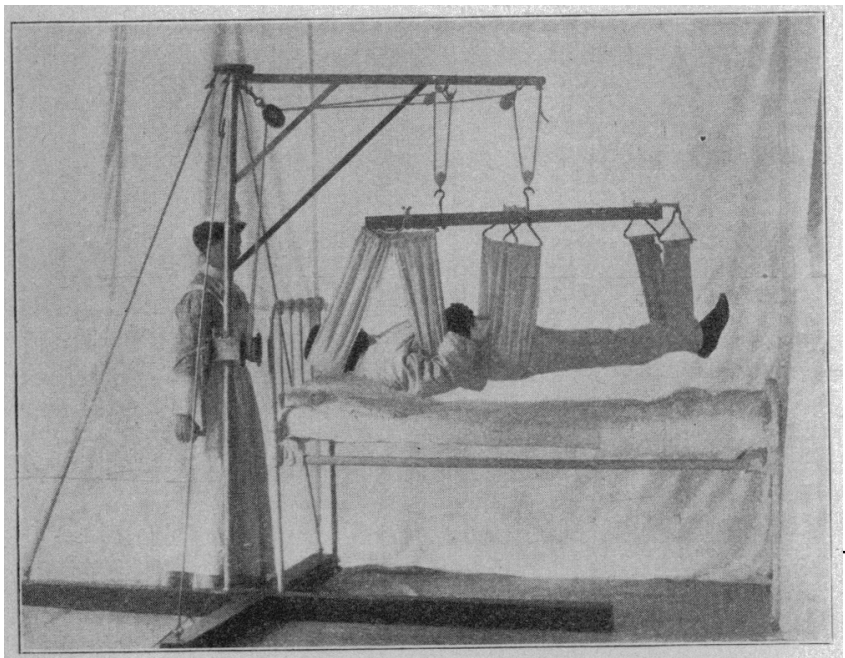

Figure 2.

still at perfect rest when so lifted. This method of introducing the straps can also be used when, on account of excessive weight, it is more difficult to pull the hip strap down under the pelvis.

Aside from making nursing easier, the apparatus, in many cases, proves a veritable Godsend to the patient. The rest to the back after being lifted is rery great. This is especially noticeable after operations, and is most useful for a long time after such operations as nephrorrhaphy, where it is undesirable for a patient to turn off from the back for some little time. Even after an ordinary laparotomy the possession of a way of lifting a patient off the back without strain contributes greatly to the taking of any tension off from the wound, such as might otherwise be due to excessive restlessness or too early turning. Of course, to that class of cases in which turning is very difficult, such as fracturs cases and chronic illnesses, the machine proves a real blessing throughout the entire sickness.

Lately I have used the machine in cases of typhoid fever at the home of the patient with most gratifying results. By swinging the crane out to the side of the bed one nurse is able to give a regular bath without strain to herself or exertion to the patient (Fig. 3). Where the means of the fam. ily are limited so that only one nurse can be engaged, this form of bed lift has really meant to the patient the difference of having the bath treatment or going without it. Each nurse who has thus far become accustomed to the use of the lift has expressed herself enthusiastically over it.

The simplicity of the machine enables it to be manufactured at comparatively slight cost, Charles E. Dressler, 143 East Twenty-third street, having reproduced the one here presented at a most reasonable figure.

In one family in which the expense of a nurse was out of the question, and in which the mother lay for several months

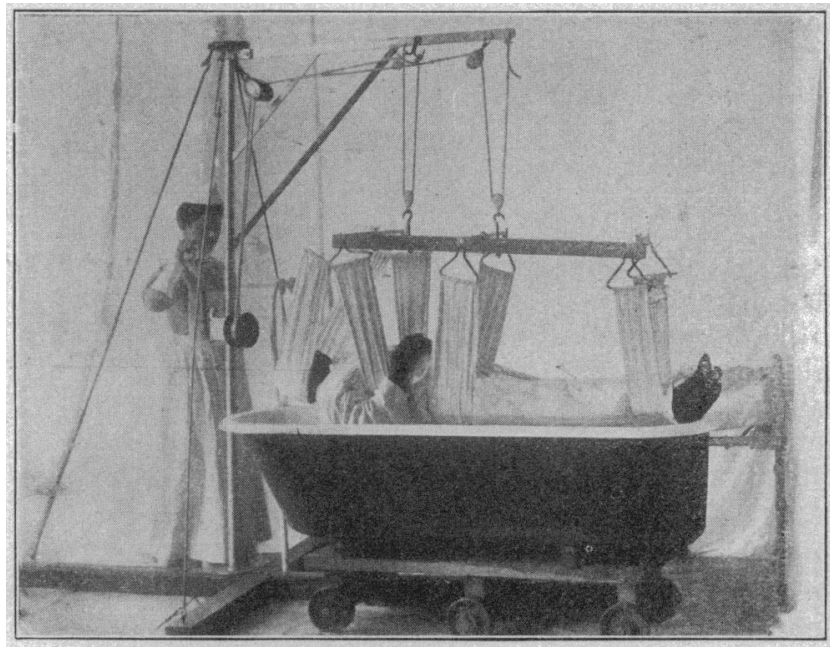

Figure 3.

dying from secondary carcinoma of the liver, being absolutely bed-ridden, and before death weighing over 200 pounds, this apparatus enabled the two daughters to care for their mother, to make her comfortable, and to keep her back and bed in good condition until she died.

\section{Clinical Note}

\section{OONGENITAL DISLOCATION OF THE HIP. REDUCTION AT AN EARLY AGE.* PRESCOTT LE BRETON, M.D. BUFFALO, N. Y.}

In cases of congenital dislocation of the hip diagnosis is possible soon after the child begins to walk, because the limp in unilateral cases or the waddle and lordosis in bilateral cases call attention to the condition.

In a certain number of cases, which are, nevertheless, congenital, dislocation does not occur until a later time. The period depends on the amount of deformity present.

* Read at a meeting of the lighth District Branch of the Medical Soclety of the State of New York. Ang. 17, 1906. 
'This fact was well illustrated in the case of a child under my observation. When 2 years old she had a waddling gait and slightly increased lordosis, but not one symptom of dislocation could be discovered. Three months later the waddle and lordosis had increased and all the typical signs of a double dislocation were present. Complete luxation occurred between the examinations.

There is considerable difference of opinion as to the time that treatment should be begun in these early cases. Some orthopcdists, notably Lorenz, prefer to wait until the third year, when diapers can be dispensed with. Others argue that it is best to reduce at once, in spite of the inconvenience in trying to keep the child clean. Their reasons for doing this are that it is much easier to reduce the dislocation at this time, complications are less likely, the period of treatment is short and the outcome more favorable because time has not allowed further changes to develop in the joint and neighboring -oft parts. In regard to this matter Lorenz ${ }^{1}$ says:

Before beginning treatment, I wait not merely till the disrepancy in the gait declares itself beyond any question, but till the child is able to keep itself clean. Then, for reasons which are easily deduced, the treatment is so much simplified that I am accustomed to wait till the expiration of the second year hefore attempting reduction. It pleases me most if the chilIren come to me for treatment after the expiration of the third year. By this time the unclean accompaniments following reduction are done away with; and on the other hand there is the important advantage that the greater tone of the soft parts materially enhances the stability of the primary position after the reposition is brought about, and so increases the chances for permanent reduction.

Ridlon ${ }^{2}$ believes that those who have operated on cases under 2 years appreciate that, while it was perhaps more easy to return the head to the acetabulum than in the older cases, it was more difficult to keep it there. Wilson ${ }^{3}$ thinks that, while it might appear on the surface that the earlier replacement is made the better it would stay, the fact exists that if the child is unable to walk a very important factor in the result is lost.

On the other hand we have the following opinions. Hoffa ${ }^{4}$ says :

In my opinion, the earlier children with congenital dislocation of the hip are subjected to treatment, the better will be the results.

Heusner ${ }^{5}$ thinks that early infancy, with its energetic wrowth, offers the best prospects for regeneration, while lelay invites rapid aggravation of the deformity.

Freiberg ${ }^{8}$ says :

The earliest possible replacement must be considered an important desideratum. The results amply justify the great additional care which is necessary to prevent the dressings from becoming soiled.

He reports the case of a child of 17 months of age, in which he obtained a good result. Bartow ${ }^{7}$ reports three similar early cases, with good results. He also modifies the plaster cast in such a way as to prevent soiling. Hoffa covers the plaster cast with a solution of rubber to make it impervious to moisture.

The following case may be added to others in which treatment was instituted early:

C. S. P., male, aged 20 months, was referred by Dr. Dean, Mayville, N. Y., August, 1905. Family history, negative.

Personal History.-A first child. Labor had been prolonged

1. Yorenz: Am. Jour. Orthopedic Surgery, vol. i1, p. 231.

2. Ridlon: Am. Jour. Orthopedic Surgery, vol. 1il, p. 154.

3. Wilson: Am. Jour. Orthopedic Surgery, vol. lii, p. 15.

4. Iloffa: Am. Iour. Orthopedic Surgery, vol. ii, p. 239

7. Heusner: Phil. Med. Jnur. Feb. 14. 1903, p. 309.

6. Frelberg: Am. Med., March 5, 1904.

7. Bartow: Am. Iour. Orthopedic Surgery, vol. iii. p. 147. for twenty-four hours, but neither force nor instruments had been employed. Baby was always in good health. For the previous two months, since he began to walk, a limp was noticed. This was so marked that it was really a Iunge forward and downward on the right leg at every step. The child, however, made no complaint, but played and ran about freely.

Examination.-All the signs of a typical unilateral dislocation were found. The right leg was three-quarters of an inch shorter than the left. The trochanter was above Nelaton's line. On placing the finger on the upper edge of the trochanter and the thumb on the anterior spinous process, and then applying intermittent traction to the leg, the trochanter very plainly slid up and down under the finger, showing a lack of firm apposition between the femur and the pelvis. The right thigh was half an inch less in circumference than the left. The gluteal muscles of the right side showed a slight atrophy. There was no spasm. Motions were very free except abduction, which was slightly limited. On rotation, the trochanter did not move in the are of a circle. On flexing and adducting the thigh, the head of the femur could be felt under the gluteal muscles. An $x$-ray picture, taken by $\mathrm{Dr}$. W. W. Plummer. showed the elevation of the trochanter on the right side. It also seemed to show anteversion of the femoral neck.

Operation.-On Aug. 29, 1905, reduction was accomplished under chloroform anesthesia by the Lorenz method. The replacement was not difficult. The apposition was firm, and it was necessary to bring the thigh down from the Lorenz posi. tion to full extension before redislocation occurred, when the bone would jump suddenly back on the dorsum of the ilium. When reduced, there was the usual shortening of the hamstrings. The plaster spica was protected by rubber dam and the mother was instructed in detail about the care of the skin. A high shoe allowed free walking.

Postoperative Bistory. - The child was sent home, returning in November, when the hip was examined and found in good condition. Dislocation did not occur even when the thigh was brought down parallel to the opposite one. In this extended position the legs were of equal length, and the firmness of the reposition argued well for the future. A new cast was applied with flexion reduced to 45 degrees, and with lessened abduction. On Feb. 3, 1906, a similar state was found, and the flexion was further reduced. On March 24, there was found for the first time a distinct fulness in front of the acetabulum near the anterior inferior spine, which disappeared during thigh flexion. The inference was plain that, owing to the deformed neck of the femur, the result would be an anterior transposi. tion. A removable spica was made for night use, to hold the thigh during sleep in the primary position. This was con. tinued for six weeks. A half-inch raise in the left shoe con. tinued a slight abduction of the right leg.

Examination on July 2 showed a functional cure. The fulness could be felt, as before, in front of the acetabulum. The legs were of equal length and circumference. No limp and no increase of lordosis. The child appeared normal, and had had perfect freedom from restraint for over two months.

\section{REMARKS.}

It would seem that in this case, at least, a wait for a periorl of a year or over would have been a mistake. The mother did not complain of the extra trouble involved in caring for the child, and she was successful, inasmuch as no cast had to be changed because of soiling. The baby grew rapidly during its confinement, playing contentedly every day. The result obtained is the same as in the majority of cases, i. e., a functional cure by anterior transposition. Permanent replacement of the head in the acetabulum is obtained in a small minority of cases only. The frequency of this forward position of the hear of the femur is supposed to be due to the anteverted neck and the shortening of the pelvi-trochanteric muscles, which latter is caused by the primarr position of Lorenz. As the leg is finally brought to ful! extension these two factors throw the head forward ont of the acetabulum. 